\title{
Effect of Inventiveness and Novelty to Competitive Advantages and Performance of Creative Industry in Tangerang
}

\begin{abstract}
Rodhiah
Faculty of Economics University of Tarumanagara Jakarta, Indonesia

*Corresponding author: rodhiah@fe.untar.ac.id

ABSTRACT

Creative industry (CI) is the most important thing in the global economy. Companies, which operate in the creative sector, represent the most innovative businesses. This research is intended to consider the influence of inventiveness, novelty and competitive advantage on the result of the creative industry. There were 110 creative industry SMEs in the handicraft sector. The sampling technique used was purposive sampling based on considering the creative industry criteria for the handicraft sector which had been operating for at least 3 years. Data collection was done by distributing questionnaires to respondents selected as members of the sample. Data obtained will be analyzed by SEM using Partial Least Square (PLS). The result of the research showed that innovation has a good and powerful effect on what makes an institution or individual better than the other rival. Creativity has a definite and substantial result on competitive advantage. Innovation directly does not have a significant effect on company achievements. Creativity directly has a positive and significant effect on company performance. Competitive advantage directly has a definite and significant effect on the performance of the company. Creativity has an indirect impact on performance mediated by competitive advantage. Therefore, craft products must be able to increase creativity and innovation to remain superior in competition and achieve optimal business performance.
\end{abstract}

Keywords: Creativity, Innovation, Excellence Competitive, Craft Sector

\section{INTRODUCTION}

Creative industries are one of the economic sources that play a role in increasing economic growth. Howkins [4] introduced economic growth depending on new ideas that are creative and innovative. The increasing development of market players in seizing the portion of the market has caused the creative industry to implement clear, structured and systematic innovative and creative product strategies.

To compete in the global market, one of the most important things for the creative industry is to increase creativity for product innovation that must be carried out on an ongoing basis based on what the market needs [8]. Inventiveness in the form of product novelty must carried out continuously, so it can be success in developing product innovation and creativity is expected to create a competitive advantage and increased business performance [11].

To improve business performance the role of innovation is a determining factor for success in achieving sustainable competitive advantage [10]. Where through these advantages will have an effect on improving business performance.

Economic development towards the creative industry is one form of optimism for aspirations to support progress in the country of Indonesia. The creative economy in the creative industry is currently highly contributing to the nation's economy. And in Indonesia, seeing creative industries in various sub-sectors must begin with development, because the Indonesian people are very rich in human resources and cultural heritage. Creativity is needed for industry, to create a competitive advantage. Steiner [13] showed that the concept of competitive advantage can encourage a company's strategy and have an impact on higher corporate performance. Based on these conditions it is important to research the craft subsector in the Tangerang region as an effort to maintain a sustainable competitive advantage and improve sustainable performance through aspects of creativity and innovation. 
From the results of initial observations made during the Harkopnas exhibition at ICE BSD in 2017, it shows a variety of creative products owned by the city of Tangerang, among others: handicrafts made from bamboo, woven, snake skin, batik, fashion, flowers from beads, bags and so on.
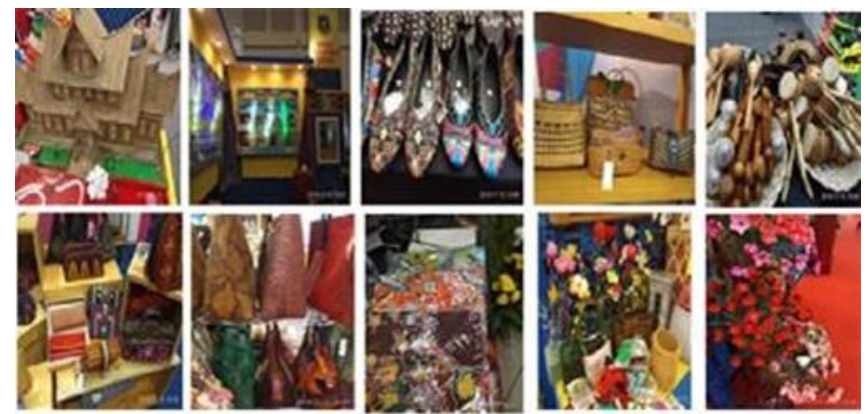

Figure 1. Banten Creative Industry Potential

Creative industry competition is getting tougher. So, inteniveness and novelty are needed to adapt to changing environments. Continuous novelty requires adequate resources, in the areas of human, financial and technological resources, small and medium-sized resources have an impact on capabilities within an organization [5]. The improvement of inventiveness and novelty is one of the fundamental items that drives the production of competitive advantage and improving market performance craft industry in Tangerang.

Based on these conditions, the problem in the background of the research above, the researcher desires to identify the problem of the influence of creativity and innovation on result performance and competitive advantages. Contribution of this study is to give priority to companies for the creative industries to: 1) to compete with attention to inventiveness and novelty. 2) provide data to pay attention about improving business creativity and continuously from the product because inventiveness and novelty are necessary in increasing competitive advantage and business result.

\section{LITERATURE REVIEW}

The ability of company to provide better customer value than competitors can create competitive advantage. Through inventiveness and novelty, it is expected to be able to form competitive advantages and ultimately improve the performance of a business. For that, it can be made in one research model in Figure.1.

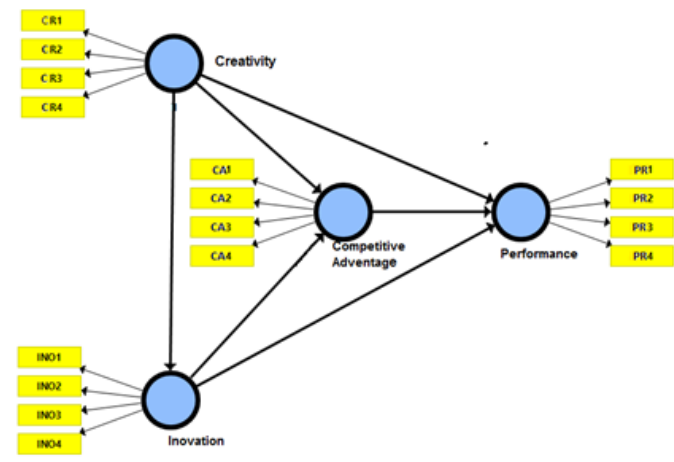

\author{
Note: Creativity $(\mathrm{CR})$ \\ Innovation (INO) \\ Competitive advantage (CA) \\ Performance (PR)
}

The creation of business performance is indispensable in increasing competitive advantage, while competitive advantage is needed to success in the global market. Inventiveness and novelty are needed by creative corporation to grow and develop. To accomplish business objective, creative industry players must have the ability to develop novelty and product creativity, where creativity and novelty are needed in generating competitive advantage and increasing business operation.

Inventiveness is a prerequisite for novelty generations [8]. Innovation is very much needed as an endeavor of entrepreneurs and a businessperson to take advantage of change as a business opportunity for different type of products or services. Innovation significantly influences competitive advantage, so the greater the ability of novelty is, the greater the competitive advantage. This is consistent with the earlier research which explain that the strength to innovate influences competitive advantage [17]. High inventiveness and novelty can upgrade company result. [12]. The output of inventiveness and progress novelty in small and medium-sized companies actually influences community performance [10].

Creativity is a qualification for generations of inventiveness and novelty unable to raise innovatively [14]. Similarly, the result of the study showed that individual creativity is not able to encourage successful innovation [15]. Based on the result of the study, the research hypothesis (H1) is creativity influences innovation.

Reference [6] argued that in principle creativity influences competitive advantage, which in principle the theory of fundamental creativity at $3 \mathrm{~T}$ is (tolerance, talent, and technology. For that research hypothesis (H2): Creativity influences Competitive Advantage

The innovation process can make a competitive advantage for the business [1] and novelty can drive the creation of competitive advantage [17]. For that research hypothesis (H3): Innovation affects Competitive Advantage.

To achieve business creative industries must have the ability to face challenges, formulate the right strategy, this condition can be affecting their performance [3]. For that research hypothesis (H4): Creativity influences performance.

The researcher found that innovation significantly affected the performance of service companies. This case gives an information that the higher the innovation of the product produced, the more higher company's performance. For this reason, hypothesis (H5): Innovation affects performance

Figure 2 Model Specifications 
The competitive advantage [11]; will have an effect on improving business performance. For that research hypothesis (H6): Competitive Advantage influences Performance.

The ability of inventiveness and novelty through oneupmanship will improve company performance [9]. For that research hypothesis:

H7: Creativity has an indirect effect on performance mediated by the variable competitive advantage.

H8: Innovation has an indirect impact on result mediated by variable competitive advantage.

\section{METHODS}

The technique used is purposive sampling, because the respondents selected as samples have predetermined criteria in accordance with the research objectives, namely entrepreneurs who have established their businesses for at least 3 years craft business sector, minimum of 3 employees, willing to participate in filling out the questionnaire, open own business and live in Tangerang. In this study, the sample was 110 entrepreneurs of creative sector handicraft products in Tangerang.

Data collection was carried out by distributing questionnaires with the format of the questionnaire using a modified Likert scale moving from 1 to 7 from strongly disagree to strongly agree. The analysis technique will be used to test hypotheses through structural equation models with at Least Partial Square (PLS) approach. The approach through free distribution is a strong research technique in Partial Least Square (PLS), because it does not consider certain distributed data but can be nominal, ordinal, interval and ratio and the samples number does not have to be large [2]. Data analysis methods in this study is divided into two, namely the measurement model (outer model) is used to test the validity and reliability and the structural model (inner model) is used to test causality (hypothesis testing with predictive models).

\section{RESULTS AND DISCUSSIONS}

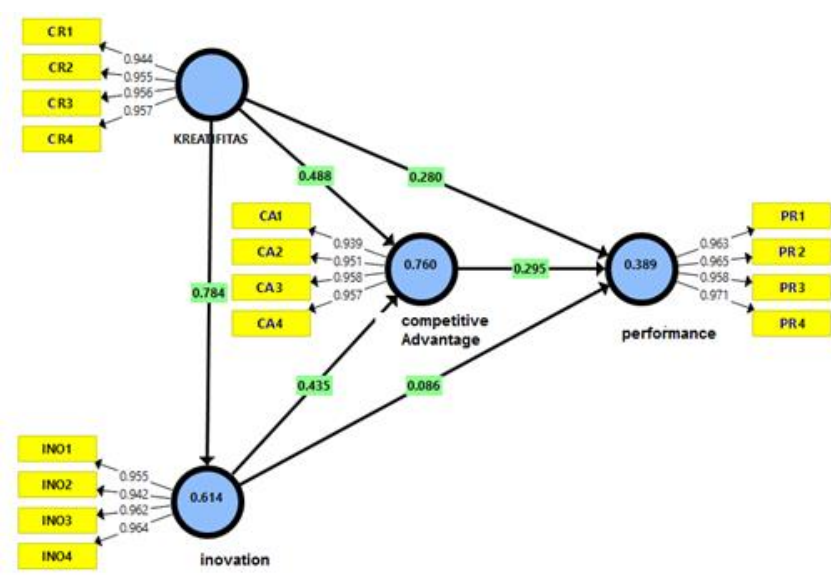

Figure 3 Result of Estimating the PLS Model - Algorithm
Based on the estimation from PLS model in the figure above, whole indicators have a loading aspect value over 0.7 indeed whole indicators are declared valid in measuring the construct. In addition to showing the value of the loading aspect of each indicator, validity of convergent was also assessed from the AVE values of each construct; the PLS model was declared to have met validity of convergent if the AVE value of each construct was more than 0.7.

The estimation result of the model as a sample to analyze the theorem in this case can be looked in the following figure.

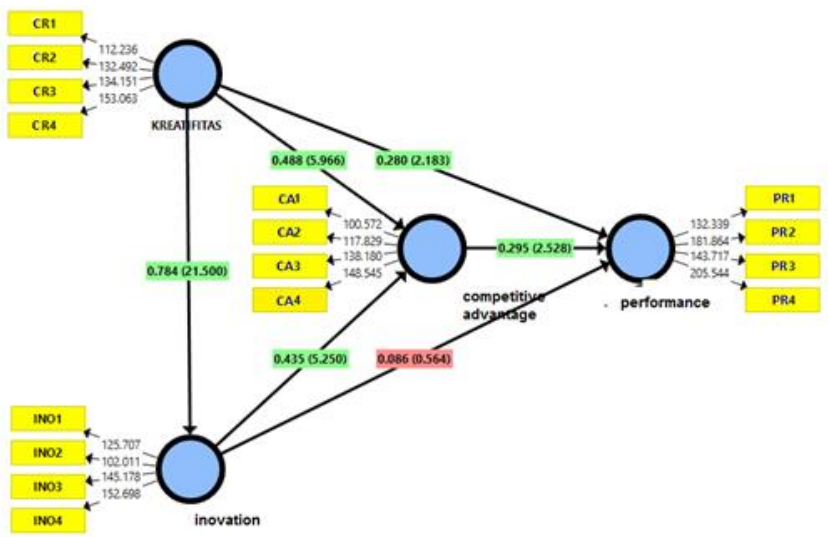

\section{Figure 4 Model Test Hypothesis Result}

Based on the computation of the PLS model with the bootstrapping technique above, there is 1 path with a $\mathrm{T}$ value below 1.96. The conclusion of the complete significance test can be listed in the next table

Table 1. Result of Direct Effect Significance Test:

\begin{tabular}{|l|l|l|l|l|l|}
\hline & $\begin{array}{c}\text { Original } \\
\text { Sample } \\
(\mathrm{O})\end{array}$ & $\begin{array}{c}\text { Sample } \\
\text { Mean } \\
(\mathrm{M})\end{array}$ & $\begin{array}{c}\text { Standard } \\
\text { Deviation } \\
(\text { STDEV })\end{array}$ & $\begin{array}{c}\text { T-Statistics } \\
(\text { OO/STDEV| }\end{array}$ & $\begin{array}{c}\mathrm{P} \\
\text { Values }\end{array}$ \\
\hline $\begin{array}{l}\text { CR -> } \\
\text { INO }\end{array}$ & 0.784 & 0.783 & 0.036 & 21.500 & 0.000 \\
\hline $\begin{array}{l}\text { CR -> } \\
\text { CA }\end{array}$ & 0.488 & 0.485 & 0.082 & 5.966 & 0.000 \\
\hline CA $->$ & 0.435 & 0.437 & 0.083 & 5.250 & 0.000 \\
\hline $\begin{array}{l}\text { CR -> } \\
\text { PR }\end{array}$ & 0.280 & 0.270 & 0.128 & 2.183 & 0.029 \\
\hline $\begin{array}{l}\text { INO -> } \\
\text { PR }\end{array}$ & 0.086 & 0.092 & 0.153 & 0.564 & 0.573 \\
\hline CA -> & 0.295 & 0.300 & 0.117 & 2.528 & 0.012 \\
\hline
\end{tabular}


Table 2. Result of Indirect Influence Test

\begin{tabular}{|l|r|r|r|r|c|}
\hline & $\begin{array}{c}\text { Original } \\
\text { Sample } \\
(\mathrm{O})\end{array}$ & $\begin{array}{c}\text { Sample } \\
\text { Mean } \\
(\mathrm{M})\end{array}$ & $\begin{array}{r}\text { Standard } \\
\text { Deviation } \\
(\text { STDEV })\end{array}$ & $\begin{array}{r}\text { T Statistics } \\
(\text { OO/STDEV| }\end{array}$ & $\begin{array}{c}\mathrm{P} \\
\text { Values }\end{array}$ \\
\hline $\begin{array}{l}\text { CR }-> \\
\text { CA -> } \\
\text { PR }\end{array}$ & 0.144 & 0.146 & 0.065 & 2.231 & 0.026 \\
\hline $\begin{array}{l}\text { INO -> } \\
\text { CA -> } \\
\text { PR }\end{array}$ & 0.128 & 0.131 & 0.057 & 2.238 & 0.026 \\
\hline
\end{tabular}

Based on the result of the analysis, it is shown that the result of the hypothesis test is obtained as follows:

Hypothesis 1: Creativity influences innovation

The amount of $p$-value for the leverage of creativity on innovation ( $\mathrm{CR} \rightarrow \mathrm{INO}$ ) is 0,000 it can be concluded that creativity has a positive and significant effect on innovation. This supports the first hypothesis. Creativity is a qualification for generations of inventiveness and novelty unable to raise innovatively [14].

Hypothesis 2: Innovation influences competitive advantage

The amount of the p-value of the result of innovation on competitive advantage (INO $\rightarrow \mathrm{CA}$ ) is 0.000 with a statistical $t$ is concluded that innovation has a definite and substantial result on competitive advantage. This supports the second hypothesis. This is consistent with the earlier research which explain that the strength to innovate influences competitive advantage [17].

Hypothesis 3: Creativity influences competitive advantage

The value of $\mathrm{p}$-value for the influence of creativity on competitive advantage ( $\mathrm{CR} \rightarrow \mathrm{CA})$ is 0,000 it can be concluded that creativity has a definite and substantial impact on competitive advantage. This supports the third hypothesis. Reference [6] argued that in principle creativity influences on competitive advantage.

Hypothesis 4: Innovation influences competitive advantage

The amount of the p-value of the result of innovation on competitive advantage (INO $\rightarrow \mathrm{CA}$ ) is 0,000 with a statistical $\mathrm{t}$ is concluded that innovation has a definite and substantial result on competitive advantage. This supports the second hypothesis. This is consistent with the earlier research which explain that the strength to innovate influences competitive advantage [17]. High inventiveness and novelty can upgrade company result [12].
Hypothesis 5: Creativity influences performance

The amount of the p-value of the effect of inventiveness on performance (CR $\rightarrow$ PR) is 0.029 with a statistical $\mathrm{T}$ of 2.183. and the path coefficient is positive, it can be concluded that creativity directly has a definite and substantial effect on the performance of the firm. The more higher company's creativity will be the higher the company's performance. This supports the fifth hypothesis.

Hypothesis 6: Innovation influences performance

The amount of the p-value effect of innovation on performance (INO $\rightarrow$ PR) it can be concluded that innovation directly does not have an important impact on company result. This does not support the fourth hypothesis. The competitive advantage [11] will have an effect on improving business performance

Hypothesis 7: Competitive Advantage influences Performance

The amount of p-value for the effect of creativity on performance (CA $\rightarrow$ PR) is 0.012 with a statistical $\mathrm{T}$ of 2.528. and the path coefficients are positive, it can be concluded that competitive advantage directly has a definite and substantial result on the act of the company. This supports the sixth hypothesis. The ability of inventiveness and novelty through one-upmanship will improve company performance [9].

Hypothesis 8: Creativity has an indirect impact on performance interceded by the variable competitive advantage

The amount of p-value indirect leverage of inventiveness on performance through competitive advantage is equivalent to 0.029 because it can be concluded that competitive advantage can mediate the indirect effect of creativity on performance which means the measurement is supporting the research hypothesis. Inventiveness in the form of product novelty must carried out continuously, so it can be success in developing product innovation and creativity is expected to create a competitive advantage and increased business performance [11].

\section{CONCLUSION}

Creativity has a definite and substantial effect on innovation. The higher company's creativity, the more innovation the company creates. Creativity has a definite and substantial impact on competitive advantage. The higher company's creativity, the more company's competitive advantage. Innovation has a definite and substantial effect on competitive advantage. The more companies can create product innovations, the higher the company's competitive advantage. Creativity directly has a definite and substantial effect on company performance. The higher company's creativity, the more company's performance. Innovation does not have a substantial impact on company performance. Competitive advantage directly has a definite and substantial effect on the performance's company. The higher the company's competitive advantage, the higher the company's 
result. Creativity has an indirect impact on performance mediated by competitive advantage. Innovation has an indirect impact on performance mediated by competitive advantage.

\section{REFERENCES}

[1] Y. Chen, C. Chang, The Determinants of Green Product Development Performance: Green Dynamic Capabilities, Green Trans-formational Leadership, and Green Creativ $\neg$ ity, Journal of Business Ethics, 2013, pp. 116: 107-19.

[2] I. Ghozali, Apikasi Analisis Multivariat dengan Program SPSS 21, Semarang: Badan Penerbit Universitas Diponegoro, 2013.

[3] M. A. S. A. Halim, S. Muda, W. A. A. W. M. Amin, The Measurement of Entrepreneurial Personality and Business Performance in Terengganu Creative Industry, International Journal of Business and Management, 6 (6) , 2011, pp. 183-93.

[4] J. Howkins, The Creative Economy: How People Make Money From Ideas, England-UK: Penguin Books, 2013.

[5] C. M. Jardon, M. S. Martos, Intellectual Capital as Competitive Advantage in Emerging Clusters in Latin America, Journal of Intel-lectual Capital, 13 (4), 2013, pp. 462-81.

[6] C. Martinez, G. M. Guzman, C. Martinez, The Relationship between Market Orientation and Innovation in Mexican Manufactur-ing SME'S, Advances in Management and Ap $\neg$ plied Economics, 3 (5), 2013, pp. 125-37.

[7] S. E. Mehrabani, Knowledge Management and Innovation Capacity, Journal of Management Research, 4 (2), 2012, pp. 164-177.

[8] L. Ren, G. Xie, K. Krabbendam, Sustainable Competitive Advantage and Marketing Innovation within Firms, Management Research Review, 31 (1), 2010, pp. 79-89.

[9] M. M. Rosli, S. Sidek, The Impact of Innovation on the Performance of Small and Medium Manufacturing Enterprises: Evidence from Malaysia, Journal of Innovation Manage $\neg$ ment in Small \& Medium Enterprise, 2013, pp. 1-16.

[10] S. N. Russell, H. H. Millar, Exploring the Relationships among Sustainable Manufacturing Practices, Business Performance, and Competitive Advantage: Perspectives from a Developing Economy, Journal of Management and Sustainability, 4 (3), 2014, pp. 37-54.

[11] I. M. Salim, M. Sulaiman, Organizational Learning, Innovation and Performance: a Study of Malaysian Small and Medium Sized Enterprises, International Journal of Business and Management, 6 (12), 2011, pp. 118-26.

[12] S. Y. Sohn, C. S. Jung, Effect of Creativity on Innovation: Do Creativity Initiatives Have Significant Impact on Innovative Perfor-mance in Korean Firms?, Creativity Research Journal, 22 (3), 2010, pp. 320-28.

[13] G. Steiner, The Concept of Open Creativity: Collaborative Creative Problem Solving for Innovation Generation-a System Approach, Journal of Business \& Management, 15 (1), 2009, pp. 5-33.

[14] Suliyanto, Rahab. The Role of Market Ori $\neg$ entation and Learning Orientation in Improving Innovativeness and Performance of Small and Medium Enterprises, Asian Social Science, 8 (1), 2012, pp. 134-145.

[15] B. Wingwon, Effects of Entrepreneurship, Organization Capability, Strategic Decision Making and Innovation toward the Competitive Advantage of SMEs Enterprises, Journal of Management and Sustainability, 2 (1), 2012, pp. 137-51. 